\title{
Performance differences of Rhode Island Red, Bashang Long-tail Chicken, and their reciprocal crossbreds under natural cold stress
}

\author{
Shanshan Xie ${ }^{1}$, Xukai Yang ${ }^{1}$, Yahui Gao ${ }^{1}$, Wenjie Jiao ${ }^{1}$, Xinghua $\mathrm{Li}^{1}$, Yajie Li ${ }^{1}$, and Zhonghua Ning ${ }^{1, *}$
}

* Corresponding Author: Zhonghua Ning Tel: +86-010-62732741, Fax: +86-010-62732741,

E-mail: ningzhh@cau.edu.cn

'National Engineering Laboratory for Animal Breeding and MOA Key Laboratory of Animal Genetics and

Breeding, College of Animal Science and Technology, China Agricultural University, Beijing 100193, China

Submitted Dec 13, 2016; Revised Jan 6, 2017; Accepted Feb 16, 2017
Objective: The Bashang Long-tail chicken (BS), an indigenous Chinese breed, is considered cold tolerant. We selected BS, the Rhode Island Red (RIR), and their reciprocal crossbreds for the present study. The objectives were: i) to validate whether BS is cold tolerant and whether egg production and cold tolerance of crossbreds could be improved; and ii) to determine the physiological characteristics that underlie cold tolerance and favorable egg production performance in cold environments.

Methods: A total of 916 chickens were reared in warm and natural cold environments (daily mean ambient temperature varied from $7.4^{\circ} \mathrm{C}$ to $26.5^{\circ} \mathrm{C}$ in the warm environment and from $-17.5^{\circ} \mathrm{C}$ to $27.0^{\circ} \mathrm{C}$ in the cold environment). To investigate their adaptability to the cold environment, the egg production performance and body weight were monitored and compared between breeds and environments. The cloacal temperature and serum biochemical parameters were monitored to reveal the physiological characteristics underlie cold tolerance and favorable egg production performance in the cold environment.

Results: The warm environment experiment showed that RIR had the highest egg production performance, and that the reciprocal crossbreds had a higher egg production performance than BS. While in the cold environment RIR had the lowest egg production performance, and the reciprocal crossbreds had a higher egg production performance than BS. In the cold environment $\mathrm{BS}$ and reciprocal crossbreds had higher triiodothyronine, tetraiodothyronine levels than RIR. At 35 and $39 \mathrm{wk}$ of age, when the ambient temperature was extremely low (varied from $-20^{\circ} \mathrm{C}$ to $0^{\circ} \mathrm{C}$ ), serum glucose, follicle-stimulating hormone, luteinizing hormone, estradiol of BS and crossbreds were higher than RIR.

Conclusion: Bashang Long-tail chicken has a favorable cold tolerance ability. Crossbreeding with RIR and BS is an effective way to develop cold tolerant chickens with improved egg production performance.

Keywords: Cold Stress; Serum Biochemical Parameters; Cloacal Temperature; Egg Production Performance; Bashang Long-tail Chicken; Rhode Island Red

\section{INTRODUCTION}

Birds have a higher body temperature compared to mammals, which makes them more vulnerable to cold environments [1,2]. Constantly increasing requirements for animal welfare and for the production of high quality animal food have resulted in free-range chicken production systems becoming more widespread [3]. However, modern high performance commercial strains, which have been selected under specific conditions, do not adapt well to realistic environments $[4,5]$. In natural environment, cold stress is one of the prominent challenges, especially in cold regions. Previous studies have shown that cold stress affects the development, health and welfare of chickens [6-8]. Frequently, climate events, like extreme low temperature weather conditions, always cause great economic losses [6,9]. Thus, there is a need to develop cold tolerant chickens for regions that experience extreme cold. 
The Bashang Long-tail chicken (BS), found in northern China, is considered to be a cold tolerant breed [10], as it is adapted to the climate and geography of the Bashang region $\left(41^{\circ} 14^{\prime}-41^{\circ} 56^{\prime} \mathrm{N}\right.$, $114^{\circ} 50^{\prime}-116^{\circ} 04^{\prime} \mathrm{E}$; average altitude of $1,418 \mathrm{~m}$, mean annual temperature of $1.9^{\circ} \mathrm{C}$ ). Another remarkable feature of $\mathrm{BS}$ is favorable egg-laying performance under the natural environmental conditions of that region (about 150 eggs/hen per year according to local records). These are the main reasons that BS was selected for the present study.

Previous studies have reported that White Leghorns crossed with Bedouin fowl (a breed that is adapted to desert conditions and can withstand both hot summers and cold winters) can produce chickens that are similarly well adapted [6]. Other studies report that Fayoumi, a heat tolerant breed, can be crossed with other breeds to produce crossbreds with improved adaptation and fitness traits [11]. Thus, crossing BS with a commercial line to produce cold tolerant high performance laying chickens might be feasible. The objectives of the present study were to: $\mathrm{i}$ ) validate whether BS is cold tolerant and whether egg production performance and cold tolerance of the crossbreds could be improved; and ii) determine the physiological differences that underlie cold tolerance and favorable egg production performance in cold environments.

\section{MATERIALS AND METHODS}

\section{Animal care}

The animal care protocol used in the present study was approved by The Animal Welfare Committee of China Agricultural University (permit number: DK996).

\section{Animals}

We first obtained 120 BS chickens (20 males +100 females; $14 \mathrm{wk}$ of age) from a poultry conservation farm in the Bashang region, northern China. Another group of 110 RIR chickens (20 males+ 90 females; 14 wk of age) were obtained from a local layer breeding corporation in Beijing, China. To obtain the sample population of BS, RIR, and their reciprocal crosses (RMBF, RIR males cross BS females; RFBM, RIR females cross BS males), the females of each breed were evenly and randomly assigned to two groups ( 2 groups $/$ breed $\times 2$ breeds $=4$ groups), and reared in individually housed stair-step cages at the Zhuozhou Farm facility of China Agricultural University. When the laying rate of BS and RIR reached $60 \%$, the two groups of females of each breed were artificially inseminated with the semen of either BS or RIR (once every four days). Eggs were collected for 14 consecutive days and stored at $20^{\circ} \mathrm{C}$. These eggs were then hatched at the farm. We obtained more than 450 birds/group on May 1, 2015. After being hatched, the chicks were artificially sexed and individually marked with numbered wing-bands. Birds were kept together during brooding and in rearing cages from the time of hatching to $14 \mathrm{wk}$ of age. The lighting and feeding programs were followed the farm mana- gement guide for RIR. Briefly, nutrient requirements were followed recommendations of the NRC [12].Start pullets with 20 to 22 hours of continuous and 30 lux light during the first week of age, after which it was reduced to 10 lux and was reduced weekly to reach 10 hours at 10 weeks of age. From 17 weeks of age, the light was gradually increased in increments of 5 lux and 1 hour per week to 20 weeks of age.

For the adult birds of the four groups (BS, RIR, RMBF, and RFBM) used in the present study, the basic morphological information was provided here. Most of the BS birds have a yellow body with a black tail; the other colors found in BS include brown, black, white and speckled. The BS cock has a long tail feather which length is about 40 to $50 \mathrm{~cm}$. The eggshell color of BS is brown and egg weight is about $54.2 \mathrm{~g}$. Adult BS female weight is $1,645.6 \mathrm{~g}$ ( $22 \mathrm{wk}$ of age). For RIR, the bird's feathers are rustcolored. The eggshell color of RIR is brown and egg weight is about $60.5 \mathrm{~g}$. Adult RIR female weight is $1,699.3 \mathrm{~g}$ ( $22 \mathrm{wk}$ of age). For the two crossbreds, most of the birds have yellow and brown feathers, the other colors found include black, white and speckled. The eggshell color of the crossbreds is brown and egg weight is about $57.5 \mathrm{~g}$. Adult female weight of the crossbreds is $1,686.3 \mathrm{~g}$ for RMBF and 1,673.3 $\mathrm{g}$ for RFBM (22 wk of age).

\section{Experimental design and treatment}

We designed the study as two parts, a warm environment experiment (used as a control) and a cold environment experiment. The purpose of the warm environment experiment is to investigate egg production performance of the four groups (BS, RIR, and their reciprocal crossbreds) under optimal conditions. While the cold environment experiment was set to test the egg production performance changes of the four groups compared to their counterparts under the warm environment, which can indicate the cold tolerance of the four groups. Moreover, for the four groups under the cold environment, their serum biochemical parameters, cloacal temperature $(\mathrm{Tc})$ and body weight $(\mathrm{BW})$ were monitored to find the underlying physiological characteristics of the four groups.

The cold environment experiment was conducted under conditions of a natural cold environment, from September 1, 2015 to January 29,2016, during the autumn and winter seasons in Beijing, China. Four groups of chickens (BS, RIR, RMBF, RFBM) were reared from 18 to 39 weeks of age for this study. On September 1, 2015, 102 healthy 18-wk-old females of each group were randomly selected and transferred to 12 identical half-open sheds $(0.17 \mathrm{~m} 2 /$ bird, 34 chickens/shed, 3 replicates/group; natural cold environment) at an ecological ranch in the Yanqing County of Beijing $\left(40^{\circ} 26^{\prime} \mathrm{N}, 116^{\circ} 05^{\prime} \mathrm{E}\right.$, average altitude of $\left.520 \mathrm{~m}\right)$ with ad libitum access to water and feed. All sheds $(2 \times 3 \mathrm{~m})$ included a patch of sandy ground $(2 \times 1 \mathrm{~m})$ and were individually enclosed by woven wire fencing and equipped with perches $(18 \mathrm{~cm} / \mathrm{bird})$, nests ( 1 per 6 hens), nipple drinkers, a feeder, a feed silo, and slatted floors $(2 \times 2 \mathrm{~m}$, suspended $0.5 \mathrm{~m}$ above the ground $)$. A 
conveyor belt running along the back of the nests collected the eggs. Another four groups of birds ( $\mathrm{n}=102,18$-wk-old) were reared in individually housed stair-step cages $\left(688 \mathrm{~cm}^{2} /\right.$ bird), under standard housing conditions (warm environment), at the Zhuozhou Farm facility of China Agricultural University. Adjacent hens (34 birds) were set as a replicate, so there were three replicates per group in the warm environment. Under both environments, all birds received $16 \mathrm{~h}$ of light per day. The daily ambient temperature $(\mathrm{Ta})$ range was recorded with maximum minimum centigrade thermometers (TFA Dostmann, Reicholzheim, Germany; $\pm 1^{\circ} \mathrm{C}$ ), and no differences were found between sheds at any given time. The daily mean $\mathrm{Ta}$ was calculated as the mean of the daily maximum and minimum temperatures (daily mean Ta varied from approximately $7.4^{\circ} \mathrm{C}$ to $26.5^{\circ} \mathrm{C}$ in the warm environment and from $-17.5^{\circ} \mathrm{C}$ to $27.0^{\circ} \mathrm{C}$ in the natural cold environment). Relative humidity was recorded with digital hygrometers (TFA Dostmann, Germany), and no differences existed between sheds at any given time (in the warm environment: approximately $28 \%$ to $85 \%$; and in the natural cold environment: approximately $19 \%$ to $92 \%$ ).

\section{Egg production performance}

The daily egg-laying performance was recorded. The weekly laying rate was calculated as follows:

$$
\begin{aligned}
& \text { Weekly laying rate } \\
& =\frac{\text { Total number of eggs produced during } 7 \text { days }}{\text { Total number of hen - day sin the same period }}
\end{aligned}
$$

\section{Sampling and parameters measurement}

The BW, Tc, and serum biological parameters (glucose [GLU], triglycerides [TRI], triiodothyronine [T3], tetraiodothyronine [T4], follicle-stimulating hormone [FSH], luteinizing hormone [LH], and estradiol [E2]) of the birds reared under the natural cold environment were monitored. The BW was monitored throughout the study with 20 birds weighted every time. Tc was measured at 22, 27, 31, 34, 36, and 39 wk of age with 20 birds measured every time. At 20,27, and 31 wk of age, serum biological parameters were measured with 12 birds were measured every time; while at 35 and $39 \mathrm{wk}$ of age, 25 birds were measured to increase statistical power. To minimize disturbances, all sampling and measurements were conducted at 19:00 $\mathrm{h}$ and were completed within $2 \mathrm{~h}$. Birds were randomly selected from sheds for sampling and measurements. The Tc was measured with a digital thermometer (Citizen CTE502; $\pm 0.11^{\circ} \mathrm{C}$ ). Blood samples $(3 \mathrm{~mL})$ were collected from the brachial vein into plastic vacuum tubes, which were kept in an incubator over night at $37^{\circ} \mathrm{C}$ for clotting. Then the clot was removed by centrifugation (Eppendorf 5804R, Hamburg, Germany) and the resulting supernatant serum was carefully collected using a pipette. Serum samples $(1 \mathrm{~mL})$ were stored at $4^{\circ} \mathrm{C}$ until further analysis. The concentrations of GLU and TRI were analyzed by an automatic biochemical analyzer (RA-1000, Bayer Corp., Tarrytown, NY, USA) using colorimetric methods, following the instructions of the corresponding reagent kits (Zhongsheng Biochemical Co., Ltd., Beijing, China). Serum T3, T4, E2, FSH, and LH were tested using commercially available ${ }^{125}$ I-labeled radioimmunoassay (RIA) kits (Beijing Sino-uk institute of Biological Technology, Beijing, China). Of these parameters, T3, T4, and E2 RIA kits were validated for measurements on chicken samples $[13,14]$; however, FSH and LH RIA kits were validated on human samples. All serum samples were analyzed within $48 \mathrm{~h}$.

\section{Statistical analysis}

Data was analyzed using SPSS (SPSS for Windows Release 20.0, SPSS Inc.; Armonk, NY, USA). The egg production performance data was analyzed with two-way analysis of variance using the general linear models procedure. The main effects of rearing environment (temperature), genotype and the interaction between them were tested. The simple main effects analysis was performed to determine the mean difference in egg production performance between groups at each rearing environment, as well as between rearing environments for each group. The BW, Tc and serum biochemical parameters were analyzed using the mixed model, with a completely randomized, repeated measure design. Significant differences were determined using the least squares differences test with $5 \%$ probability.

\section{RESULTS}

\section{Egg production performance}

The weekly laying rate of the four groups reared in the warm environment is presented in Figure 1A. The peak laying rate of RIR, BS, RMBF, and RFBM were $94.8 \%, 76.8 \%, 94.5 \%$, and $93.1 \%$ respectively. The average number of eggs produced per hen at $39 \mathrm{wk}$ of age was 130.7, 91.1, 117.6, and 121.1 for RIR, BS, RMBF, and RFBM, respectively. The number of RIR eggs was higher than that of RMBF and RFBM ( $\mathrm{p}=5.0 \times 10^{-4}$ and $\mathrm{p}=6.0 \times 10^{-3}$ respectively), which in turn were higher than that of BS (both $\mathrm{p}<1.0$ $\times 10^{-4}$; Table 1 ).

The weekly laying rate of the four groups reared in the natural cold environment is presented in Figure 1B. The peak laying rate of RIR, BS, RMBF, and RFBM were $67.1 \%, 73.8 \%, 87.5 \%$, and $80.4 \%$, respectively. The average number of eggs produced per hen at 39 wk of age was 57.7, 70.5, 84.16, and 78.62 for RIR, BS, RMBF, and RFBM, respectively. The egg number of RMBF and RFBM was higher than that of $\mathrm{BS}\left(\mathrm{p}=3.0 \times 10^{-4}\right.$ and $\mathrm{p}=1.6 \times 10^{-2}$ respectively), which in turn were higher than that of RIR ( $\mathrm{p}=$ $0.0011 .0 \times 10^{-3}$, Table 1).

As shown in Figure 1, it is evident that the cold environment adversely affected egg production performance. During the whole experimental period, the average number of eggs produced by each group reared in the natural cold environment was lower than that reared in the warm environment $\left(\mathrm{p}<1.0 \times 10^{-4}\right.$ for all groups). The interactions of environment by genotype have a 

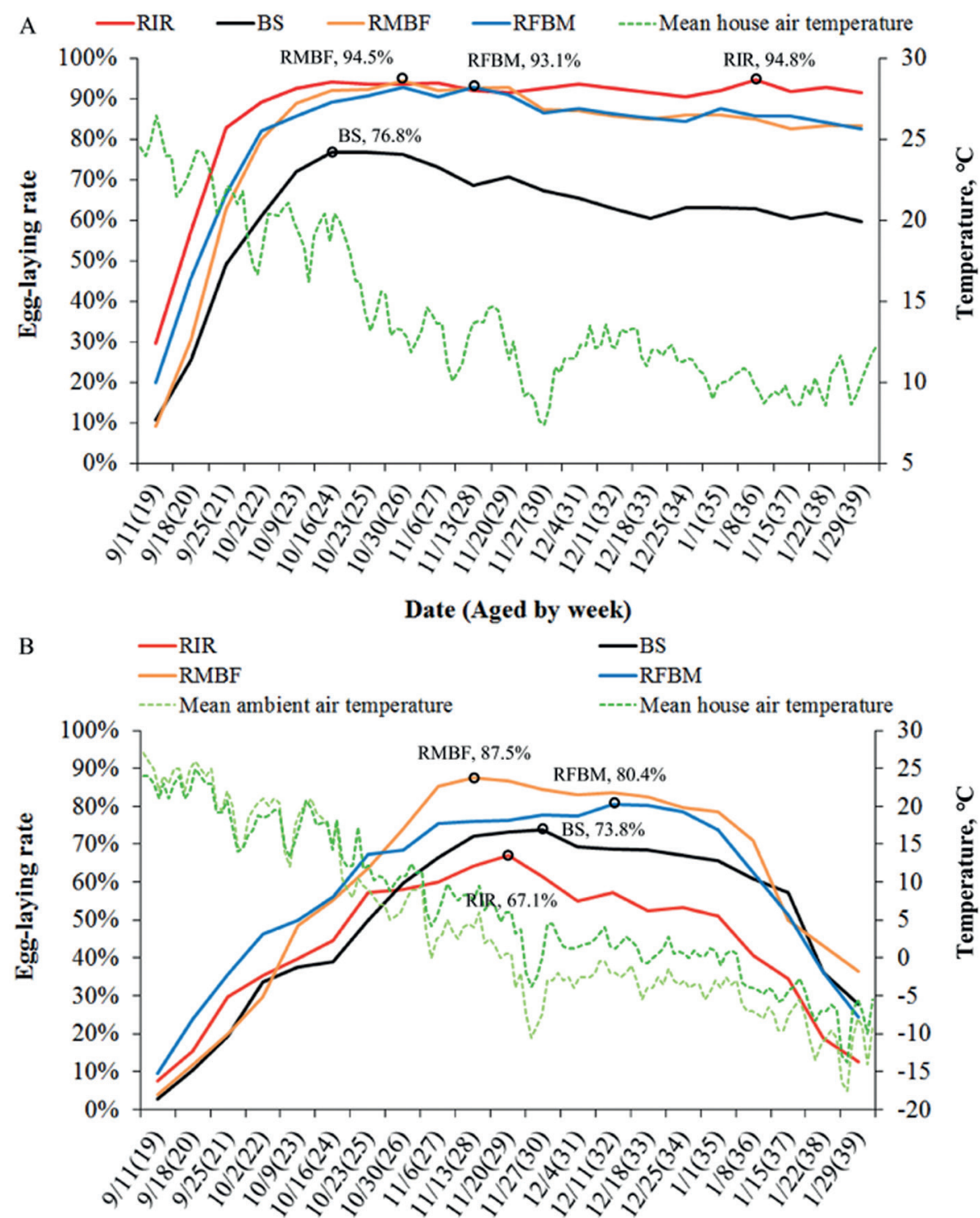

Date (Aged by week)

Figure 1. Weekly laying-rate of the four groups reared in the warm and natural cold environments. (A) Weekly laying-rate in the warm environment. (B) Weekly laying-rate in the natural cold environment. Circled points represent the peak laying-rate of each group. X-axis: date (aged by week). RIR, Rhode Island Red; BS, Bashang Long-tail chicken; RMBF, RIR males cross BS females; RFBM, RIR females cross BS males.

statistically significant effect on the egg production performance $\left(\mathrm{p}<1.0 \times 10^{-4}\right.$, Table 1$)$. The results also showed that the egg production performance of the crossbreds was improved under conditions of natural cold environment.

\section{Body weight}

The BW changes between groups reared in the natural cold environment are presented in Figure 2. Before $34 \mathrm{wk}$ of age, BW of each group increased gradually and no significant differences

Table 1. Egg production performance and number of dead birds of the four groups during the whole experimental period under both cold and warm environments

\begin{tabular}{|c|c|c|c|c|c|c|c|c|c|c|c|}
\hline & \multicolumn{4}{|c|}{ Cold } & \multicolumn{4}{|c|}{ Warm } & \multicolumn{3}{|c|}{$p$-value } \\
\hline & BS & RIR & RMBF & RFBM & BS & RIR & RMBF & RFBM & $E$ & G & $E \times G$ \\
\hline Egg No. & $70.5^{B}$ & $57.7^{c}$ & $84.16^{A}$ & $78.62^{\mathrm{A}}$ & $91.1^{c}$ & $130.7^{\mathrm{A}}$ & $117.6^{B}$ & $121.1^{\mathrm{B}}$ & $<0.01$ & $<0.01$ & $<0.01$ \\
\hline Egg mass/hen (g) & $3,823.9^{B}$ & $3,488.0^{c}$ & $4,839.2^{A}$ & $4,523.8^{A}$ & $4,941.3^{C}$ & $7,900.8^{A}$ & $6,762.0^{B}$ & $6,968.1^{B}$ & $<0.01$ & $<0.01$ & $<0.01$ \\
\hline Dead birds No. & 3 & 3 & 2 & 4 & 0 & 1 & 0 & 0 & $\mathrm{Na}$ & $\mathrm{Na}$ & $\mathrm{Na}$ \\
\hline
\end{tabular}

BS, Bashang Long-tail chicken; RIR, Rhode Island Red; RMBF, RIR males cross BS females; RFBM, RIR females cross BS males; E, environmental effects; G, genotype effects; Ex G, interactions of environment by genotype; $\mathrm{Na}$, not available.

${ }^{A-C}$ Means within each parameter at the same time with different superscript letters are significantly different $(p<0.01)$. 


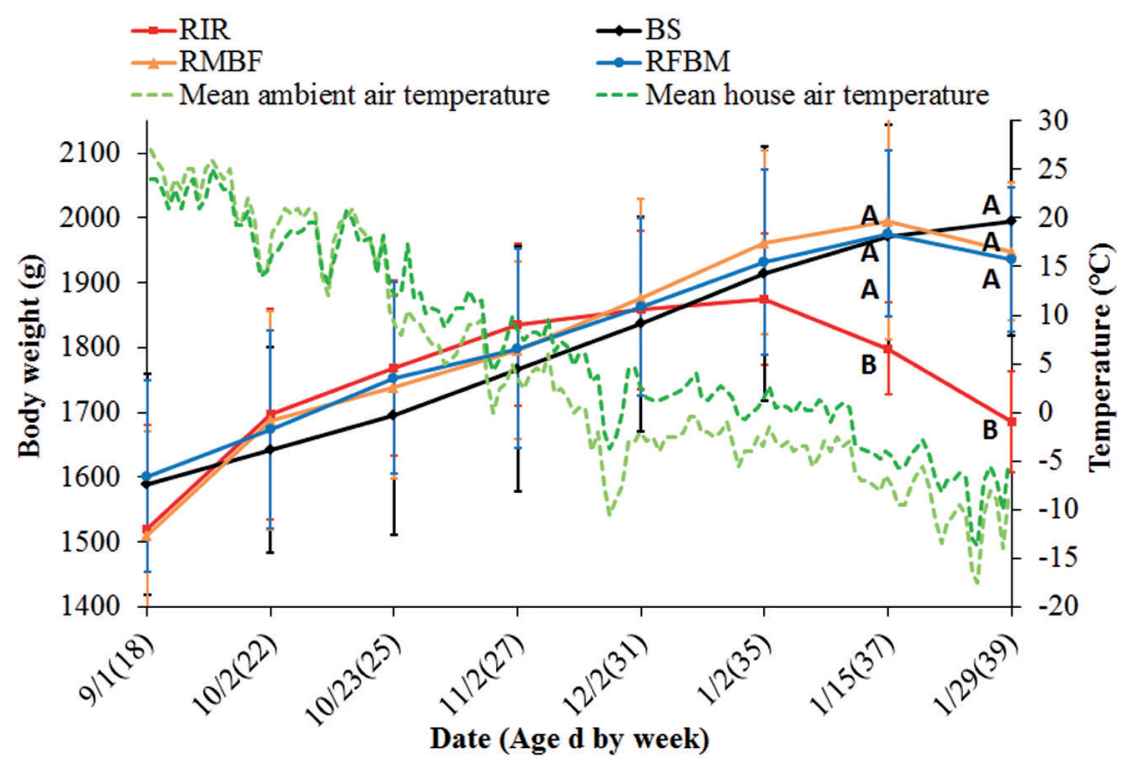

Figure 2. Body weight (mean \pm standard deviation) of the four groups reared in the natural cold environment. $A, B$ at the same time point, different letters indicate significant difference $(p<0.01)$. X-axis: date (aged by week). RIR, Rhode Island Red; BS, Bashang Long-tail chicken; RMBF, RIR males cross BS females; RFBM, RIR females cross BS males.

were observed between groups. However, at 37 and $39 \mathrm{wk}$ of age, when the Ta was below $-5^{\circ} \mathrm{C}$ (varied from $-17.5^{\circ} \mathrm{C}$ to $-5^{\circ} \mathrm{C}$ ), the BW of RIR declined and fell to a value that was lower than that of the other three groups $\left(\mathrm{p}<1.0 \times 10^{-4}\right)$.

The mean BW of RIR at $37 \mathrm{wk}$ of age $(1,798.2 \mathrm{~g})$ was lower than that at $34 \mathrm{wk}$ of age $\left(1,875.7 \mathrm{~g}, \mathrm{p}=1.0 \times 10^{-3}\right)$, and that at 39 wk of age $(1,685.2 \mathrm{~g})$ was lower than that at 37 wk of age $(\mathrm{p}=$ $\left.1.0 \times 10^{-4}\right)$. The BW of crossbreds was also reduced at $39 \mathrm{wk}$ of age, but was not significantly lower than that at $37 \mathrm{wk}$ of age ( $\mathrm{p}=0.15$ for RMBF and 0.13 for RFBM). BS was the only breed to show no reduction in $\mathrm{BW}$ and kept steadily increasing throughout the entire experimental period.

\section{Cloacal temperature}

Variations in Tc between groups reared in the natural cold environment are presented in Figure 3. As the Ta decreased, the Tc of BS showed a reduction from 22 to $34 \mathrm{wk}$ of age $\left(\mathrm{p}<1.0 \times 10^{-4}\right)$. The Tc of RMBF and RFBM showed a slight reduction and that of RIR showed a slight increase throughout the experimental period.

\section{Serum biochemical parameters}

Table 2 and Table 3 show the effects of group, time and the interactions between them on serum biochemical parameters in the natural cold environment. T3 and T4 levels of BS and the cross-

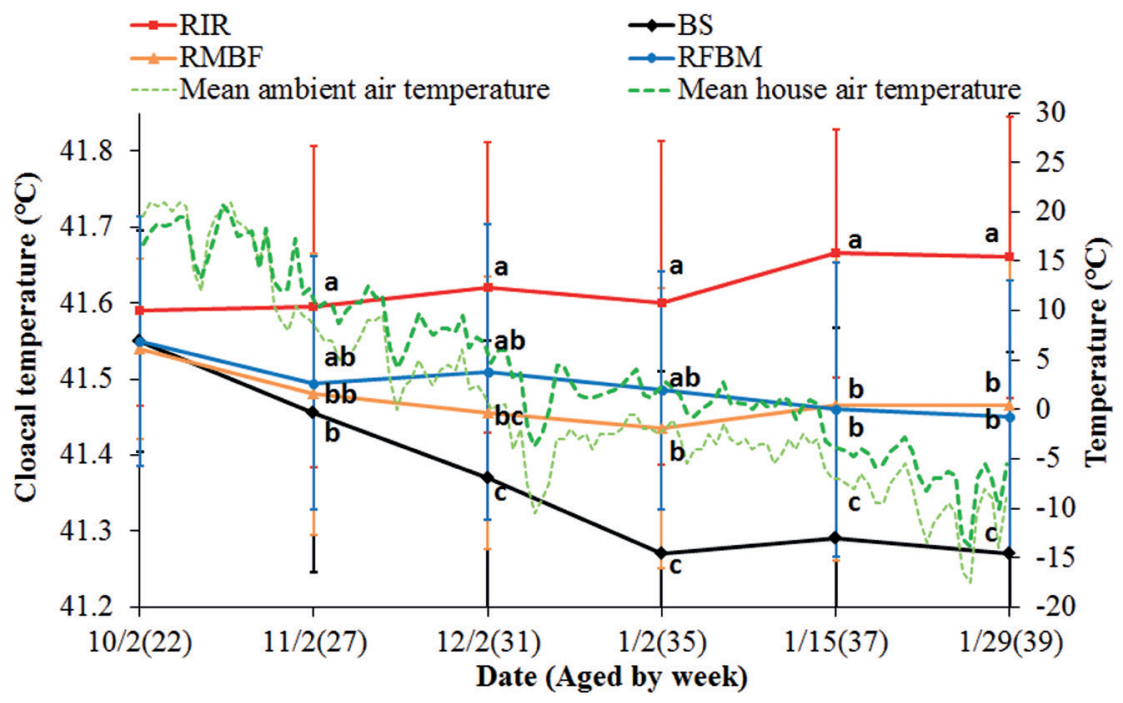

Figure 3. Cloacal temperature (mean \pm standard deviation) of the four groups reared in the natural cold environment. ${ }^{a \cdot c}$ The same time point, different letters indicate significant differences between groups $(p<0.05)$. X-axis: date (aged by week). RIR, Rhode Island Red; BS, Bashang Long-tail chicken; RMBF, RIR males cross BS females; RFBM, RIR females cross BS males. 
Table 2. p-Value for the influence of group, time and their interactions on biochemical parameters in the natural cold environment

\begin{tabular}{lccccccc}
\hline Item & GLU & TRI & T3 & T4 & FSH & LH & E2 \\
\hline Group $^{1)}$ & 0.14 & 0.61 & 0.00 & 0.00 & 0.002 & 0.001 & 0.09 \\
Time $^{2)}$ & 0.00 & 0.00 & 0.997 & 0.00 & 0.00 & 0.003 & 0.00 \\
Group $\times$ time $^{2}$ & 0.002 & 0.03 & 0.52 & 0.002 & 0.00 & 0.004 & 0.03 \\
\hline
\end{tabular}

GLU, glucose; TRI, triglycerides; $T 3$, triiodothyronine; $T 4$, tetraiodothyronine; $F S H$, follicle-stimulating hormone; LH, luteinizing hormone; E2, estradiol; RIR, Rhode Island Red; $B S$, Bashang Long-tail chicken; RMBF, RIR males cross BS females; RFBM, RIR females cross BS males.

1) Groups: RIR, BS, RMBF, and RFBM.

${ }^{2)}$ Time: 20, 27, 31, 35 and 39 wk of age.

breds were higher than those of RIR at 27,31,35, and 39 wk of age (Table 3, p < 0.05). GLU, FSH, LH, and E2 levels of BS and the crossbreds were higher than those of RIR at 35 and $39 \mathrm{wk}$ of age (Table 3, $\mathrm{p}<0.05$ ). Levels of TRI were comparable between groups throughout the study.

During the whole experimental period, the total number of dead birds of each group under both environments are shown in Table 1.

\section{DISCUSSION}

Cold environments can dramatically affect health, performance and welfare of chickens. Over the past few decades, most breeding programs have only considered the economically relevant traits and have generally ignored the fitness related traits [4]. On the other hand, there is a drastic difference between the environment of selection and that of production. In reality, animals face acute heat or cold exposure, gradual seasonal changes in temperature, and changes in diurnal temperature cycles. Thus, their ability to adapt to such environmental conditions has become an important issue. As results, many problems about production performance and welfare arose in the actual production environment [15]. In the present study, we examined the egg production performance of RIR, BS, and their reciprocal crossbreds. The results show that cold stress negatively affects egg production performance, a finding that is consistent with previous studies [6]. Under the natural cold environment, BS was the only breed to show no reduction in BW and kept steadily increasing throughout the entire experimental period, which suggests RIR is more vulnerable to cold environments. It also shows that the egg production performance of the crossbreds was higher in the natural cold environment. This suggests that crossing RIR with cold tolerant BS is an effective way to improve egg production performance in natural cold environments. Similarly, previous studies on Bedouin and Fayoumi strains have demonstrated that their crosses with commercial lines effectively improved performance of the crossbreds in suboptimal environmental conditions [6].

Homeothermic animals develop adaptive modifications to cope with Ta fluctuations that include adjustments in metabolism, insulation, and behavior [16]. Previous studies in birds have demonstrated that lower critical temperatures are reduced and metabolism is increased, as Ta decreases. The present results showed that when Ta fell below a threshold of $-5^{\circ} \mathrm{C}$, the $\mathrm{BW}$ of RIR was significantly reduced, and that of the crossbreds was just

Table 3. Serum biochemical parameters of the four groups reared in the natural cold environment (mean \pm SD)

\begin{tabular}{|c|c|c|c|c|c|c|c|c|}
\hline Age (date) & Group & $\mathrm{GLU}(\mathrm{mmol} / \mathrm{L})$ & TRI (mmol/L) & $\mathrm{T} 3$ (ng/mL) & $\mathrm{T} 4$ (ng/mL) & $\mathrm{FSH}(\mathrm{mlU} / \mathrm{mL})$ & $\mathrm{LH}(\mathrm{mlU} / \mathrm{mL})$ & E2 (pg/mL) \\
\hline \multirow{4}{*}{$\begin{array}{l}20 \text { wk } \\
\text { (1 Oct) }\end{array}$} & RIR & $11.42 \pm 1.40$ & $9.44 \pm 0.94$ & $0.54 \pm 0.11$ & $23.45 \pm 7.29^{b}$ & $6.66 \pm 1.02^{2 b}$ & $11.24 \pm 1.53$ & $233.08 \pm 30.04$ \\
\hline & BS & $10.94 \pm 1.07$ & $9.49 \pm 0.52$ & $0.54 \pm 0.11$ & $25.52 \pm 5.90^{\mathrm{ab}}$ & $7.39 \pm 1.45^{\mathrm{a}}$ & $11.60 \pm 1.34$ & $228.89 \pm 27.67$ \\
\hline & RMBF & $10.65 \pm 1.17$ & $9.19 \pm 1.22$ & $0.59 \pm 0.12$ & $27.80 \pm 6.74^{\mathrm{a}}$ & $6.02 \pm 0.90^{b}$ & $10.78 \pm 1.76$ & $208.51 \pm 16.74$ \\
\hline & RFBM & $10.76 \pm 1.21$ & $9.27 \pm 1.21$ & $0.53 \pm 0.07$ & $24.03 \pm 5.20^{b}$ & $6.84 \pm 1.28^{\mathrm{ab}}$ & $10.23 \pm 1.32$ & $196.93 \pm 21.58$ \\
\hline \multirow{4}{*}{$\begin{array}{l}27 \text { wk } \\
(6 \mathrm{Nov})\end{array}$} & RIR & $12.30 \pm 1.25$ & $6.48 \pm 0.15$ & $0.45 \pm 0.07^{b}$ & $11.69 \pm 2.53^{c}$ & $6.35 \pm 0.64$ & $12.63 \pm 1.429$ & $419.20 \pm 113.21$ \\
\hline & BS & $11.84 \pm 1.26$ & $6.62 \pm 0.09$ & $0.59 \pm 0.11^{\mathrm{a}}$ & $24.68 \pm 5.30^{\mathrm{a}}$ & $6.43 \pm 1.03$ & $13.75 \pm 1.459$ & $397.22 \pm 85.08$ \\
\hline & RMBF & $12.02 \pm 0.74$ & $6.55 \pm 0.11$ & $0.58 \pm 0.11^{\mathrm{a}}$ & $20.98 \pm 5.45^{\mathrm{ab}}$ & $6.06 \pm 0.98$ & $13.31 \pm 2.157$ & $408.79 \pm 93.07$ \\
\hline & RFBM & $11.76 \pm 1.14$ & $6.05 \pm 0.93$ & $0.58 \pm 0.11^{\mathrm{a}}$ & $19.76 \pm 6.86^{b}$ & $6.44 \pm 1.52$ & $12.96 \pm 2.896$ & $400.33 \pm 109.68$ \\
\hline \multirow{4}{*}{$\begin{array}{l}31 \text { wk } \\
\text { (4 Dec) }\end{array}$} & RIR & $10.96 \pm 1.64$ & $5.17 \pm 0.19$ & $0.47 \pm 0.19^{b}$ & $14.69 \pm 3.30^{c}$ & $5.65 \pm 0.69$ & $11.41 \pm 1.57$ & $349.85 \pm 45.98$ \\
\hline & BS & $12.07 \pm 1.40$ & $5.22 \pm 0.14$ & $0.60 \pm 0.20^{\mathrm{a}}$ & $23.92 \pm 4.54^{\mathrm{a}}$ & $5.73 \pm 0.81$ & $12.43 \pm 2.50$ & $338.74 \pm 89.02$ \\
\hline & RMBF & $11.00 \pm 1.85$ & $5.10 \pm 0.18$ & $0.58 \pm 0.22^{\mathrm{a}}$ & $19.52 \pm 4.73^{b}$ & $6.50 \pm 0.97$ & $12.25 \pm 1.80$ & $325.91 \pm 85.45$ \\
\hline & RFBM & $11.55 \pm 2.07$ & $5.02 \pm 0.23$ & $0.58 \pm 0.16^{\mathrm{a}}$ & $18.68 \pm 3.21^{b}$ & $5.80 \pm 1.27$ & $12.19 \pm 1.64$ & $341.23 \pm 70.35$ \\
\hline \multirow{4}{*}{$\begin{array}{l}35 \text { wk } \\
\text { (1 Jan) }\end{array}$} & RIR & $10.86 \pm 1.21^{c}$ & $5.28 \pm 0.84$ & $0.41 \pm 0.15^{b}$ & $20.33 \pm 5.34^{c}$ & $5.00 \pm 1.51^{b}$ & $8.08 \pm 2.27^{b}$ & $261.01 \pm 41.55^{b}$ \\
\hline & BS & $13.05 \pm 1.79^{\mathrm{ab}}$ & $5.43 \pm 0.56$ & $0.65 \pm 0.21^{\mathrm{a}}$ & $30.88 \pm 7.68^{\mathrm{a}}$ & $6.52 \pm 2.56^{\mathrm{a}}$ & $15.14 \pm 11.41^{\mathrm{a}}$ & $266.47 \pm 81.27^{\mathrm{ab}}$ \\
\hline & RMBF & $12.52 \pm 1.75^{b}$ & $5.64 \pm 0.19$ & $0.63 \pm 0.19^{\mathrm{a}}$ & $25.21 \pm 6.53^{b}$ & $8.17 \pm 3.42^{\mathrm{a}}$ & $15.03 \pm 9.95^{\mathrm{a}}$ & $305.11 \pm 82.12^{\mathrm{a}}$ \\
\hline & RFBM & $13.76 \pm 1.56^{\mathrm{a}}$ & $5.62 \pm 0.26$ & $0.55 \pm 0.15^{a}$ & $22.49 \pm 5.66^{\mathrm{bc}}$ & $6.14 \pm 2.52^{\mathrm{ab}}$ & $11.37 \pm 5.82^{\mathrm{ab}}$ & $314.72 \pm 69.18^{a}$ \\
\hline \multirow{4}{*}{$\begin{array}{l}39 \text { wk } \\
\text { (29 Jan) }\end{array}$} & $\mathrm{RIR}$ & $11.83 \pm 1.02^{b}$ & $8.43 \pm 0.192$ & $0.46 \pm 0.07^{c}$ & $19.79 \pm 3.32^{c}$ & $6.19 \pm 0.98^{b}$ & $9.00 \pm 1.85^{c}$ & $204.62 \pm 48.60^{b}$ \\
\hline & BS & $12.95 \pm 1.09^{\mathrm{a}}$ & $8.45 \pm 0.55$ & $0.62 \pm 0.08^{\mathrm{a}}$ & $29.05 \pm 5.31^{a}$ & $7.02 \pm 1.08^{\mathrm{a}}$ & $11.08 \pm 1.76^{b}$ & $226.73 \pm 81.40^{b}$ \\
\hline & RMBF & $12.63 \pm 1.53^{\mathrm{a}}$ & $8.45 \pm 0.24$ & $0.58 \pm 0.09^{\mathrm{ab}}$ & $28.06 \pm 5.79^{a}$ & $7.09 \pm 1.37^{\mathrm{a}}$ & $12.44 \pm 2.27^{\mathrm{a}}$ & $299.32 \pm 81.65^{a}$ \\
\hline & RFBM & $12.92 \pm 1.27^{\mathrm{a}}$ & $8.46 \pm 0.22$ & $0.55 \pm 0.06^{b}$ & $24.25 \pm 5.82^{b}$ & $7.15 \pm 1.20^{\mathrm{a}}$ & $11.69 \pm 2.39^{\mathrm{ab}}$ & $282.50 \pm 77.18^{\mathrm{a}}$ \\
\hline
\end{tabular}

SD, standard deviation; GLU, glucose; TRI, triglycerides; T3, triiodothyronine; T4, tetraiodothyronine; FSH, follicle-stimulating hormone; LH, luteinizing hormone; E2, estradiol; RIR, Rhode Island Red; BS, Bashang Long-tail chicken; RMBF, RIR males cross BS females; RFBM, RIR females cross BS males.

${ }^{a-c}$ Means within each parameter at the same time with different superscript letters are significantly different $(p<0.05)$. 
slightly reduced at the lowest Ta encountered in the study, whereas the BW of BS showed a steady increase. Similarly, Spinu and Degen [6] showed that cold environments significantly reduced BW in White Leghorns, but not in Bedouin fowl, a breed adapted to desert conditions. Other studies $[8,17]$ have demonstrated that abdominal fat content is negatively affected by low environmental temperatures. In the cold environment, heat loss must be compensated with comparable levels of heat production to maintain a constant body temperature range. Therefore, reductions in BW might be due to enhanced catabolism to generate more heat. Furthermore, the feed intake of RIR was also reduced at a later stage (data not shown), and this was directly associated with the reductions in BW. Therefore, extreme cold could have an influence on the nervous system and thereby affect feed intake. In this study, the Tc of RIR was kept stable, however, it of other three groups was reduced (the Tc of BS was reduced earlier and to a much greater extent than that of RMBF and RFBM). In cold environments, a lower body temperature facilitates the minimization of heat dissipation. These results, together with egg production performance, suggest that BS was better adapted to cold environments and that the crossbreds had improved cold tolerance. During the whole experimental period, the dead birds of the four groups under both environments varied from 0 to 4 , we presume that these deaths were due to poor cold tolerance or bad health status.

Birds must increase heat production as Ta decreases, a process that entails hormonal regulation $[18,19]$. The success with which chickens cope with cold depends on their physiological ability to respond appropriately. Thyroid hormones, including T3 and $\mathrm{T} 4$, reportedly regulate thermogenesis, particularly the basal metabolic rate and cold-induced thermogenesis [20,21]. Previous studies $[8,22]$ have reported that chicken T3 and T4 levels are elevated under cold stress. Serum levels of thyroid hormones were considered to be associated with energy production [23,24]. Guo et al [25] assumed that thyroid stimulating hormone and T4 secretion are enhanced to increase the metabolic rate, as the bird adapted to colder environments. In the present study, we found that $\mathrm{T} 3$ and T4 levels were significantly higher in BS than in RIR, and those of crossbreds showed improvement to a different extent. This indicates that BS could generate more heat to keep body temperature stable in cold environments, and that the heat generating capacity of the crossbreds was also enhanced. At later stages, GLU levels of BS, RMBF, and RFBM were also significantly higher than that of RIR. Puvadolpirod and Thaxton [26] demonstrated that serum GLU is important for homeostasis.

The female reproductive system is comprised of the ovary and oviduct, and is regulated by the hypothalamus-pituitary-gonadal axis. The hypothalamus produces gonadotropin-releasing hormone $(\mathrm{GnRH})$ that stimulates the pituitary gland to produce $\mathrm{LH}$ and $\mathrm{FSH}$, two hormones that in turn regulate ovarian follicular growth and ovulation. The ovary produces gonadal steroids, primarily estradiol and progesterone that return to the central nervous system through the bloodstream, and provide feedback regulation of hypothalamic GnRH production and release [27]. Differences in egg-laying performance have been associated with differences in plasma levels of reproductive hormones, such as LH, FSH, and inhibins [28]. During the later stages of the present study, $\mathrm{LH}, \mathrm{FSH}$, and E2 of BS, RMBF and RFBM were significantly higher than that of RIR. The different concentrations of these hormones might represent indicators or factors responsible for the differences in egg-laying performance; nevertheless, the timing of the differences observed in the levels of these hormones was not synchronized with the changes observed in the egg-laying rate. Reproduction is a complicated process that involves many hormones, and is affected by physiological conditions and by the external environment [29]. It should be noted that the present study examined only three reproductive hormones (LH, FSH, and E2), and other hormones such as inhibin, progesterone, and $\mathrm{GnRH}$ were not analyzed. Some studies have reported that the effects of gonadotropins on follicular development and ovulation rate are mediated by intraovarian growth factors such as the insulin-like growth factor, bone morphogenetic proteins, and epidermal growth factor [30]. Thus, it may be possible to determine the mechanisms that favor egg-laying performance in cold environments by analyzing the levels of a greater number of reproductive hormones and indices in future studies.

In individual growth and development, the levels of biochemical parameters are in a dynamic state. These levels can be affected by age, environment changes, and physiological conditions [27]. Thus, levels of the serum biochemical parameters vary at different times. Despite the pulsatility of hormone secretion, we also observed notable variations in serum T3 and T4 levels in the present study. T3 and T4 concentrations in RIR were relatively higher at $20 \mathrm{wk}$ of age, but became lower from 27 to $39 \mathrm{wk}$ of age. In contrast, $\mathrm{T} 3$ and $\mathrm{T} 4$ concentrations of $\mathrm{BS}$ were increased to different extents from 27 to $39 \mathrm{wk}$ of age. These findings might be due to breed differences, and the levels of T3 and T4 could be potential biomarkers for future selection of cold tolerant breeds.

In summary, the present study shows that BS is more cold tolerant, and could be a potential candidate for future selection and crossbreeding of cold tolerant breeds. Crossbreds of RIR and BS exhibit both favorable cold tolerance and favorable egg production performance.

\section{IMPLICATIONS}

The present study demonstrated that crossbreeding with RIR and BS is an effective way to develop cold tolerant chickens with improved egg production performance. In this study, the birds with favorable cold tolerance and egg production performance under the cold environment showed higher serum T3 and T4 levels, as well as GLU, FSH, LH, and E2 levels. By analyzing these biochemical parameters, we can investigate the cold tolerance and egg production performance of chickens under cold environments. 


\section{CONFLICT OF INTEREST}

We certify that there is no conflict of interest with any financial organization regarding the material discussed in the manuscript.

\section{ACKNOWLEDGMENTS}

The work was supported by the Chinese Agricultural Research System (CARS-40) and the National Scientific Supporting Projects of China (2015BAD03B06).

\section{REFERENCES}

1.Siegel HS. Stress, strains and resistance. Br Poult Sci 1995;36:3-22.

2.Collier RJ, Gebremedhin KG. Thermal biology of domestic animals. Annu Rev Anim Biosci 2015;3:513-32.

3.Hurnik JF. Animal welfare: ethical aspects and practical considerations. Poult Sci 1990;69:1827-34.

4.Cheng HW. Breeding of tomorrow's chickens to improve well-being. Poult Sci 2010;89:805-13.

5.Besbes B. Genotype evaluation and breeding of poultry for performance under sub-optimal village conditions. Worlds Poult Sci J 2009;65: 260-71.

6.Spinu M, Degen AA. Effect of cold stress on performance and immune responses of Bedouin and White Leghorn hens. Br Poult Sci 1993;34: 177-85.

7.Campo JL, Prieto MT, Davila SG. Effects of housing system and cold stress on heterophil-to-lymphocyte ratio, fluctuating asymmetry, and tonic immobility duration of chickens. Poult Sci 2008;87:621-6.

8.Blahova J, Dobsikova R, Strakova E, Suchy P. Effect of low environmental temperature on performance and blood system in broiler chickens (Gallus domesticus). Acta Vet Brno 2007;76:S17-S23.

9.Nguyen PH, Greene E, Donoghue A, et al. A new insight into cold stress in poultry production. Adv Food Technol Nutr Sci 2016;2: $143-4$.

10. Qi JF. Report on domestic animal genetic resources in China (in Chinese). Beijing China: China Agriculture Press; 2004.

11. Khawaja T, Khan SH, Mukhtar N, Parveen A. Comparative study of growth performance, meat quality and haematological parameters of Fayoumi, Rhode Island Red and their reciprocal crossbred chickens. Ital J Anim Sci 2012;11:211-6.

12. National Research Council. Nutrient requirements of poultry. 9th rev. ed. Washigton, DC, USA: National Academy Press; 1994.

13. Qiao X, Zhang HJ, Wu SG, et al. Effect of beta-hydroxy-beta-methylbutyrate calcium on growth, blood parameters, and carcass qualities of broiler chickens. Poult Sci 2013;92:753-9.
14. Duan JL, Shao F, Shao YG, et al. Androgen Inhibits abdominal fat accumulation and negatively regulates the PCK1 gene in male chickens. Plos One 2013;8:e59636.

15. Dawkins MS, Layton R. Breeding for better welfare: genetic goals for broiler chickens and their parents. Anim Welf 2012;21:147-55.

16. Yahav S, Straschnow A, Plavnik I, Hurwitz S. Blood system response of chickens to changes in environmental temperature. Poult Sci 1997; 76:627-33.

17. Yunianto VD, Hayashi K, Kaneda S, Ohtsuka A, Tomita Y. Effect of environmental temperature on muscle protein turnover and heat production in tube-fed broiler chickens. Br J Nutr 1997;77:897-909.

18. Debonne M, Baarendse PJJ, Van Den Brand H, et al. Involvement of the hypothalamic-pituitary-thyroid axis and its interaction with the hypothalamic-pituitary-adrenal axis in the ontogeny of avian thermoregulation: a review. Worlds Poult Sci J 2008;64:309-21.

19. Paakkonen T, Leppaluoto J. Cold exposure and hormonal secretion: a review. Int J Circumpolar Health 2002;61:265-76.

20. Hayashi K, Kuroki H, Kamizono T, Ohtsuka A. Comparison of the effects of thyroxine and triiodothyronine on heat production and skeletal muscle protein breakdown in chicken. J Poult Sci 2009;46: 212-6.

21. Silva JE. Thermogenic mechanisms and their hormonal regulation. Physiol Rev 2006;86:435-64.

22. Yahav S. Domestic fowl - strategies to confront environmental conditions. Avian Biol Res 2000;11:81-95.

23. Hornick JL, Van Eenaeme C, Gerard O, Dufrasne I, Istasse L. Mechanisms of reduced and compensatory growth. Domest Anim Endocrinol 2000;19:121-32.

24. Shinder D, Luger D, Rusal M, et al. Early age cold conditioning in broiler chickens (Gallus domesticus): thermotolerance and growth responses. J Therm Biol 2002;27:517-23.

25. Guo JL, Zheng QH, Yin QQ, Cheng W, Jiang YB. Study on mechanism of ascites syndrome of broilers. Am J Anim Vet Sci 2007;2:62-5.

26. Puvadolpirod S, Thaxton JP. Model of physiological stress in chickens 1. Response parameters. Poult Sci 2000;79:363-9.

27. Wingfield JC, Sapolsky RM. Reproduction and resistance to stress: When and how. J Neuroendocrinol 2003;15:711-24.

28. Lovell TM, Knight PG, Groome NP, Gladwell RT. Changes in plasma inhibin A levels during sexual maturation in the female chicken and the effects of active immunization against inhibin alpha-subunit on reproductive hormone profiles and ovarian function. Biol Reprod 2001;64:188-96.

29. Ottinger MA, Bakst MR. Endocrinology of the avian reproductive system. J Avian Med Surg 1995;9:242-50.

30. Sato E. Intraovarian control of selective follicular growth and induction of oocyte maturation in mammals. P Jpn Acad B-Phys 2015;91:76-91. 